\title{
Faculty Day and the Library at Brooklyn College: A Report
}

The following two papers provide descriptions of the general library participation and the exhibit program during Faculty Day in 1953 at Brooklyn College. Since these represent efforts at integration of the library in the instructional program, the Editors have included these papers for any suggestions to librarians who have similar occasions at their institutions.

By MARGARET K. ROWELL

\section{The Library Participates in Faculty Day}

Mrs. Rowell is chief catalog librarian, Brooklyn College Library.

$\mathrm{F}$ Aculty Day" at Brooklyn College, began in 1949 at the suggestion of the Dean of Faculty, and has had as its main purpose the joint discussion by faculty members, one day each year, of the college curricula. The teaching staff then became aware of problems faced by departments other than one's own, and of possible solutions for meeting those problems. Classes are suspended except for demonstration groups. The most popular subject for Faculty Day since its inception has been the new curriculum being tried out experimentally at the College.

The Experimental Liberal Arts Curriculum began in the fall of 1949 after three years of study, exploration and planning by a Committee on Long-Term Curriculum Study set up by the Faculty Council in 1946. When Faculty Day was established, it was hoped that it might give the faculty at large an opportunity to hear how the Experimental Program was organized, to participate in panel discussions, and to see how the experiment was operating.

One of the aims of the Experimental Curriculum has been to foster independent study of world literature. The Library, cooperating with the teaching faculty on all phases of the program, was particularly interested in this goal. In the spring of 1952 , the Library Department asked for the opportunity to take part in the program of the 1953 Faculty Day in order to demonstrate to the teachers the role the Library played in the College's efforts to realize its educational goals.

According to its usual practice, the Committee for Long-Term Curriculum Study in the fall of 1952 distributed through departments a circular seeking an expression of preference for the program. In December, 1952, the Dean of Faculty announced in the "Staff Bulletin" that in accordance with the preponderant sentiment expressed by the Faculty in the poll conducted in November, the Faculty Day program in 1953 will be devoted to the "Experimental Curriculum: Its Past and Future." It was also announced that there would be two programs in the afternoon, one by the Air Force ROTC and the other by the Library. Members of the Faculty would be given the opportunity to express a choice for attendance at either of these two, as well as a choice among the morning programs offered. Attendance in the morning was required, but in the afternoon it was to be voluntary.

Preliminary plans provided for six panels in the morning session. Word came shortly after the first announcement that the Fund for the Advancement of Education had made a grant of $\$ 25,000$ to Brooklyn College to finance a study by groups of faculty members of the significant innovations of the Experimental Curriculum. The Committee for Long-Term Curriculum Study then revised its plans for Faculty Day. It decided to concentrate on three of the six subjects originally scheduled. "Independent study" was one of 
the three panels eliminated. The Library program, which we had thought would best tie up with this panel, was still to be given but would concentrate on indicating its relationship to the entire College program.

The Library Department immediately set about planning its part of the program. A Library Faculty Day Committee, under the chairmanship of the author, was established. There were two other members of the Committee. They were the Chief Acquisition Librarian to represent the point of view of librarians behind the scenes, and the Chief Reference Librarian to represent the point of view of librarians serving at public desks. The Chairman met several times with the Committee for Long-Term Curriculum Study in order to keep it abreast of the Library's plans, and to receive suggestions on the program in general. The Long-Term Curriculum Study Committee made it clear that it was particularly interested in having the Library stress its relationship to the college curriculum with emphasis on services to students as well as to faculty. Since the morning programs were to consist of panel discussions, with no more than six speakers, to be followed by a question period, the Library Committee decided to adopt the same plan for its program in the afternoon.

Experience had shown that the most successful Faculty Day programs were those in which detailed statements, outlining the topic and including possible questions for discussion were distributed about two weeks in advance of Faculty Day to all those electing to attend that particular part of the program. The Library Committee found this suggestion quite useful as it provided opportunity to give ahead of time the background information considered necessary to understand the $\mathrm{Li}$ brary Department and its position in the academic community. Also pertinent questions could be listed which would help to make the discussion period advance along lines which in the judgment of the Committee would be most beneficial.

The afternoon programs were limited to one hour. This was somewhat of a disappointment because it restricted the program. The original plans had called for an extended tour of the Library building with emphasis on those parts of the building the teachers did not ordinarily see. It had also been hoped that an integral part of the program might be a showing of Kodachrome slides of new library buildings throughout the country, since Brooklyn College contemplates building an extension to its present structure in the near future.

To make the maximum use of the hour allotted, the Library Committee decided to have two panels, $A$ and $B$, meet in two different rooms, one on the first floor and the other on the second floor. The audience, rather than the panel speakers, would move from one floor to another, so that they would be introduced to at least two of the rooms and main floors of the building. The showing of slides, an hour program in itself, was scheduled to be given after the regular program for all those who were willing to remain one hour longer.

"The Library in College Instruction" was the theme of the Library program. It was to be developed in two panel discussions, each lasting a half-hour. The subject for Panel A was "Services Behind the Scenes" and for Panel B, "Administration, and Services at Public Desks." Each session consisted of three 5-minute talks and a I5-minute question and answer period. Those attending the Library program were assigned to one of two groups on a staggered schedule.

Even though the afternoon program had to depend upon voluntary attendance, about 220 out of a faculty of approximately 500 elected to take part in the Library program. The Department was encouraged by this interest in the Library on the part of the teachers, especially as the competing program put on by the Air Force ROTC was concerned with the activities of a recent innovation on the campus and might reasonably be expected to attract many who would otherwise have little or no opportunity to learn about the offerings of the Department to a liberal arts college.

Panel A discussed acquisition, classification, cataloging and special services; Panel $\mathrm{B}$ discussed administration, circulation and reference areas. The talks cut across library organizational lines and dealt with a particular area of librarianship. Each panel had a moderator who gave a brief introductory talk and, at the end of the scheduled speeches, led the discussion.

The announcement of the Library program that had been sent out in advance to the faculty included a statement of the showing of the Kodachrome slides, as well as the ex- 
hibit concerning the Library Department. The purpose of the exhibit was to show the activities of the various library divisions to supplement the panel talks.

The main part of the advance statement was entitled "Interesting Facts About Brooklyn College Library." The facts were the legal status of the Library as an instructional department of the College, the fact that the librarians were members of the Faculty, the size of the book collection, circulation figures in 1951/1952; hours of service, number of library users in 1951/1952; size of the staff and the educational qualifications of the librarians, library finances, and library publications. A chart of the organization of the Library Department was included, with the name of the chief of each division noted. Finally there was a list of suggested questions to stimulate the question period scheduled to follow discussions.

Typical questions under Panel A were: I. Is there any formula that can be followed in deciding how many copies of a title to order for reserve use? 2. Does the Library have any special strengths and weaknesses in the collection? 3. Why does the Library not buy more materials to aid faculty research? 4. How long does it take to make a book available? 5. How can the classroom teacher help shorten the time required to make a book available?

Typical questions under Panel B were: I. How can the teacher and the librarian best cooperate to make it possible for the Library to meet the demands made upon it in the area of classroom assignments? 2. To what extent is it possible to expand library lectures to students, either within the field of their major subject interest, or as general lectures to upperclassmen? 3. Why does the Library plan to change from the traditional organization emphasizing function to that which emphasizes subject areas, primarily?

Panel A tried to convey to the teachers some understanding of the principles and procedures by which books and related materials are selected, acquired, classified and cataloged by the Library. The chief acquisition librarian, the first speaker, explained how materials are selected and acquired, the principles underlying good book selection, the divisions responsible for this area of work, the necessity for close cooperation between the teacher and the librarian in the building of a good and effective collection, and some mention of the part each plays in achieving this goal.

The chief catalog librarian, then defined classification and cataloging, and explained why both are necessary; how the materials acquired by Brooklyn College Library are organized and cataloged, listed the steps taken to make the card catalog as responsive as possible to the needs of the undergraduates, and made mention briefly of the cooperative efforts made nationally by catalogers to share the results of their bibliographical research so that all users of the Library, student and faculty alike, are greatly benefited.

The chief special services librarian discussed the "special" services offered by the Library Department. These are lectures to freshmen and some upperclassmen, publications, exhibits and public relation activities.

Panel B's first speaker, the head librarian, dealt with the area of administration, the chief librarian's responsibility for establishing and maintaining a good book collection, an efficient staff, and adequate physical facilities for housing the collection and the staff, and for providing reading area for students and faculty. The ever-present problem of finance was touched upon, and a brief mention was made of the contemplated organization of the Library Department when the extension to the present building would be erected.

The chief circulation librarian then discussed the purpose of circulation work, types of material circulated, regulations to provide effective service, provisions for recreational reading and the interlibrary loan service.

The final speaker on Panel $B$, the chief reference librarian, considered the nature of reference work, which divisions in the library gave this service, a detailed explanation of advisory services offered, and the contribution to the instructional program of the College made by means of these reference and advisory services.

The programs on Faculty Day began at Io A.M. and were scheduled to end shortly after noon. There were several speakers at the close of the luncheon, including the president of the College and one of the honored guests. Approximately Ioo teachers came to the Library.

The teachers showed a gratifying and keen interest in the entire program, asked searching questions, and studied the exhibit of the $\mathrm{Li}$ brary's organization and activities in the main lobby. Some remained the extra hour to 
watch the showing of colored slides of new library buildings. The librarians would have been happier if a larger percentage of the teaching staff had been able to participate in their program, but they were satisfied that the day itself had been a success, and that mutual understanding among teachers and librarians had been deepened.

\section{By ANTOINETTE CIOLLI}

\section{The Faculty Day Library Exhibit}

\section{Miss Ciolli is a member of the Reference} Division, Brooklyn College Library.

\section{$\mathrm{A}^{\mathrm{N}}$} INTEGRAL PART of the Brooklyn College Library's program for Faculty Day was an exhibit on services to students and faculty. This was designed as a visual supplement to the discussion presented by two panels and described by Mrs. Rowell in the preceding report.

The initial planning of the exhibit was entrusted to a steering Committee of three members of the Library Staff. The first decision to confront the Committee concerned the allocation of the available cases. Since the panel discussions were to cut across division lines, the Committee thought it best to accord each division of the Library its own display case. It was believed, too, that the core services of administration, acquisition, cataloging, circulation, and reference should be granted the central floor cases in the main lobby of the Library and that the Government Documents, Special Services, and Teacher Education exhibits should occupy the surrounding wall cases. Aside from posters and uniform embossed red and white title labels provided by the Committee, the contents of each division exhibit was left completely to the discretion of the division heads or their representatives. On the posters, a gayly colored medieval page trumpeted forth the theme of the exhibit: The Library in College Instruction.

Covering the work of each division, however, was not quite telling the complete story, for Brooklyn College librarians, in addition to being instructional members of the staff, are components of an expanding profession. The Committee therefore thought it suitable to devote the remaining cases to publications of our librarians and to books and magazines dealing with trends in the science of librarianship.
Throughout the planning the emphasis was to explain the flow of procedures and describe the varied services to students and faculty. Thus, the step-by-step journey of Alexander Heard's $A$ Two-Party South? through the Acquisition and Catalog Divisions was portrayed. The account started with the receipt of recommendation cards, and then proceeded through the checking for accurate bibliographic information and price, the sending out of orders and the final receipt of the book. Forms, checking tools and bibliographies were shown appropriately underscored with red cord.

The Catalog exhibit matched the Library of Congress cards to the book and attached a red tab to the main entry to indicate the ultimate destiny of the volume to be the Reserve Room. Tools used to catalog the book, such as the LC and ALA Rules, the Dewey Decimal Classification, the LC Subject Headings and the Cutter table, with red strings connecting the information in these lists with the corresponding information on the cards, were displayed. Also included were procedures for books and serials for which LC cards are not available. Here, samples of the Catalog Division's own typed unit cards, including foreign language cards, were shown. Headings especially adapted to Brooklyn College use but not listed by the Library of Congress were an essential part of the Catalog exhibit.

The Circulation Division then carried the narrative forward by spotlighting its IBM charging and discharging operations. A flow chart incorporated examples of transaction cards and photographs of the IBM machines. Also part of the Circulation exhibit was a sectional drawing of the Library building with areas under its supervision colored and labeled.

The Reference Division displayed examples of its reference books, pamphlets, bibliographies and indexes in the humanities, sciences, 
and social sciences, and showed a sampling of its occupational resources, bibliographies prepared by its members, and topics of research for which students sought reference assistance.

To tie together all these activities, the chief librarian and his executive assistant provided a large master chart showing in detail the administrative organization of the Library. Also featured in the chief librarian's exhibit were the services of organizations affiliated with the Library. Outstanding among these are the Library Associates of Brooklyn College, one of whose many activities is the sponsorship of an annual College-Community award to a deserving student, and the $W$ alt Whitman Foundation of Brooklyn, Inc., whose aim is to microfilm all known manuscripts of the Brooklyn poet.

In the surrounding wall cases, the Periodicals and Documents and Education exhibits demonstrated, in an arresting manner, the richness of the resources of these divisions. Each stressed material distinctive to itself.

The display of the Periodicals and Documents Division consisted of a colorful selection of current scholarly and general magazines, newspapers, indexes, microfilms and reference resources in government documents.

Indeed, the variety of the media comprising the Library prompted the Committee to bring together in a wall case entitled "Library Materials" not only examples of types of information already on display but also additional material such as maps, music scores and manuscripts. To represent the latter the Committee chose the original typescript of Frances Winwar's Farewell the Banner, one of six manuscripts presented to the Brooklyn College Library by this author.

Although each of the divisions promotes good relations with its patrons by striving to give good service, there is at Brooklyn a Special Services Division whose primary purpose is to act as liaison between the Library and its public. The Special Services exhibit, therefore, appropriately illustrated its fourfold function of publicity, exhibits, Library publications and student orientation with examples of awards it has won, handbooks and publications it edits, forms and clippings in regard to its exhibits, slides and problem sheets connected with its Library lectures to Freshmen and pages from its publicity scrap book.

With faculty attention concentrated upon the Library it was thought a good opportunity to highlight the professional literature in the field of librarianship. The Committee chose to display current issues of The $\mathrm{Li}$ brary Quarterly, Library Trends, College and Research Libraries, The Library Journal and The Wilson Library Bulletin and to feature such books as Louis Round Wilson's The Library in College Instruction; Fremont Rider's The Scholar and the Future of the Research Library; Louis Round Wilson's The Practice of Book Selection; Dorothy May Norris's A History of Cataloguing and Cataloguing Methods and Herman H. Fussler's Library Buildings for Library Service. A special case called attention to a sampling of the contributions of the Brooklyn College librarians to this literature.

Thus, for the first time in the young history of Brooklyn College Library, participation in Faculty Day provided a significant opportunity for the staff to summarize visually its resources, multiplicity of services and variety of professional activities. Both faculty and staff learn from the experience.

\section{How Little Cataloging Can Be Effective?}

\section{(Continued from page I7o)}

As I look over this paper I must confess to a sense of frustration. These things have been said so often before. And we are still so far from knowing how our catalogs are actually used, and for what uses they should be constructed. Who uses an author's dates, the notation of size, or a series note, and why? Is this title card ever consulted? Does the frequency of use justify the cost of giving collation? Until we know in fairly exact terms how much cata loging is effective, we really have no basis for discussing how little cataloging can be effective. 